\title{
Artigo
}

\section{Adsorption of Erichrome Black T from Aqueous Solution onto Expanded Perlite Modified with Orthophenanthroline}

\author{
Almeida, J. M. F.; ${ }^{*}$ Oliveira, E. S.; Silva, I. N.; De Souza, S. P. M. C.; \\ Fernandes, N. S.
}

Rev. Virtual Quim., 2017, 9 (2), 502-513. Data de publicação na Web: 3 de fevereiro de 2017

http://rvq.sbq.org.br

\section{Adsorção do Negro de Eriocromo T a partir de Solução Aquosa sobre Perlita Expandida Modificada com Ortofenantrolina}

Resumo: Neste estudo foi realizado o processo de adsorção através da análise de vários parâmetros que influenciam na remoção do corante azo, negro de eriocromo $T$, em um chamado efluente sintético (solução aquosa do corante), usando como adsorvente a perlita expandida (um aluminossilicato) modificada com ortofenantrolina (uma base de Lewis).

Palavras-chave: Perlita expandida; Negro de eriocromo T; ortofenantrolina; adsorção.

\section{Abstract}

In this study the adsorption process was performed by analyzing various parameters that influence the azo dye removal, eriochrome black $T$, a so-called synthetic effluent (aqueous dye), using as adsorbent expanded perlite (an aluminosilicate) modified with orthophenanthroline (a Lewis base).

Keywords: Expanded perlite; eriochrome black T; orthophenanthroline; adsorption.

\footnotetext{
* Federal University of Rio Grande do Norte, Laboratory of Analytical Chemistry and Environment, Institute of Chemistry, Te.: +55 84 32153828, Brazil.

$M$ janielequimicaufrn@gmail.com

DOI: $\underline{10.21577 / 1984-6835.20170029}$
} 


\title{
Adsorption of Erichrome Black T from Aqueous Solution onto Expanded Perlite Modified with Orthophenanthroline
}

\author{
Janiele Mayara F. de Almeida, * Érica S. Oliveira, Isabel do N. Silva, Sheila \\ Pricila Marques C. de Souza, Nedja S. Fernandes
}

Federal University of Rio Grande do Norte, Laboratory of Analytical Chemistry and Environment, Institute of Chemistry, Te.: +55 84 32153828, Brazil.

* janielequimicaufrn@gmail.com

Recebido em 26 de agosto de 2016. Aceito para publicação em 3 de fevereiro de 2017

\section{Introduction}

\section{Experimental section}

2.1. Characterization of the materials

2.2. Preparation of the adsorbate and adsorbent

2.3. Adsorption experiments

2.4. Equilibrium time and study of the eriochrome black $T$ initial concentration effect in the adsorption process

2.5. Effect of $\mathrm{pH}$ on the adsorption process

\section{Results and discussion}

3.1. Characterization of the materials

3.2. Equilibrium time and study of the eriochrome black $T$ initial concentration effect in the adsorption process

3.3. Effect of $\mathrm{pH}$ on the adsorption process

\section{Conclusion}

\section{Introduction}

The Eriochrome black-T is an azo dye, used widely both in textile and in research and teaching laboratories primarily as metallochromic indicator in titration complexation to determine the water hardness. ${ }^{1,2}$ A complex chemical structure of eriochrome black T offers a greater resistance to photodegradation, water, as well as certain chemical reagents, impairingthe removal or reduction of its color during the contaminated wastewater treatment. $^{3}$

With the industrial and technological advance more coloring substances are produced and used in various fields and applications, generating more and more highly toxic and difficult degradation wastes, resulting in a serious environmental problem, once that such waste is released directly to the environment without any previous treatment, which is highly detrimental to the ecosystem. Thus, several authors have been Rev. Virtual Quim. |Vol 9| |No. 2| |502-513| 
working on removal process of these contaminants mainly in aqueous environments.

Many surveys have been conducted involving the effluents treatment by using adsorbents. One example is the use of expanded perlite, characterized as an aluminosilicate which presents $71-75 \% \mathrm{SiO}_{2}$ in the composition. The expanded perlite which is an aluminosilicate with potentially acidic surface, and therefore interacts better with the dye of basic type in adsorption processes. ${ }^{4-7}$ The adsorptive capacity of the expanded perlite is attributed to the presence of silanol groups on its surface. ${ }^{8}$

The modification of adsorbent materials aims to control its physical and chemical properties so that this new material can be used for the purpose which is intended for. Perlite, in other studies in the literature, has been modified with some materials, such as humic substances and oxide of manganese, in order to modify their properties for various application. ${ }^{9,10}$

The orthophenanthroline is an organic compound, characterized as a Lewis base and widely used as a binder in coordination chemistry.

In order to improve the adsorption capacity of the expanded perlite, since the same without modification, has no affinity for the acid-type dye molecules, a fact confirmed by the literature, ${ }^{4}$ the study herein was carried out with the use of orthophenanthroline, aiming to modify the expanded perlite so that the adsorbent material can favor the Eriochrome black-T adsorption (dye acid).

According to the literature there are various methods of treating water contaminated by heavy metals and dyes standing out techniques such as chemical precipitation, ion exchange, membrane filtration, adsorption, coagulation, flocculation, flotation, and electrochemical treatment. ${ }^{11}$ The most effective method for treating water contaminated with dyes is through adsorption technique. ${ }^{3}$
Thus, effluents treatments contaminated with these dyes are highlighted within the search. In order to assess the adsorption process applicability the dye removal azo / acid Eriochrome black-T, we used the expanded perlite (amorphous aluminosilicate and naturally acid) modified orthophenanthroline (one weak organic basis) as the dye adsorbent. Parameters were investigated influencing the extension of adsorption: contact time, the dye initial concentration the $\mathrm{pH}$ solution.

\section{Experimental section}

\subsection{Characterization of the materials}

The materials (Expanded Perlite, orthophenanthroline, expanded perlite modified orthophenanthroline, eriochrome black T) were subjected to the methods TG/DTA using a thermogravimetric analyzer and simultaneously calorimeter of TA INSTRUMENTS SDTQ600 using the following conditions analysis: platinum crucible; nitrogen as purge gas; gas flow of $100 \mathrm{~mL}$ $\mathrm{min}^{-1}$; heating rate $293 \mathrm{~K} \mathrm{~min}^{-1}$ and the final temperature of $1273 \mathrm{~K}$ analysis.

To obtain the molecular absorption spectrum in the UV-Vis Eriochrome black T region, a spectrophotometer model UV-1800 Shimadzu was used, performing a scanning using a wavelength range $190-700 \mathrm{~nm}$. Quartz cuvettes were used with optical path of $1 \mathrm{~cm}$ and water as white to obtain the baseline, since aqueous solutions were used during this work. To obtain the IR spectra a FTIR-8400S IRAFFINITY-1 spectrometer was used, with the following specifications: 32 scans; analysis range of $400-4000 \mathrm{~cm}^{-1}$; resolution of $4 \mathrm{~cm}^{-1}$ using $\mathrm{KBr}$ pellets. The following materials were subjected to analysis IR materials: orthophenanthroline, expanded perlite, perlite modified orthophenanthroline and the Eriochrome black T.

To characterize the structure, parameters 
of diffraction X-XAs used a Bruker D2 Phaser device using CuK radiation $(\lambda=1.54 \AA$ ) with a $\mathrm{Ni}$ filter, with step $0,02^{\circ}$ of $10 \mathrm{~mA}$ current, voltage $30 \mathrm{kV}$ using a Lynxeye detector. Analyses were performed for expanded perlite, expanded perlite orthophenanthroline and modified orthophenanthroline.

\subsection{Preparation of the adsorbate and adsorbent}

The expanded perlite (the adsorbent) was first washed with distilled water in order to remove some impurities that may have been incorporated in the material during storage or handling. After this washing procedure the material was dried in an oven (333 K for 4 hours) and sieved on a 100 mesh sieve.

For the modification procedure of expanded perlite, it was initially prepared $250 \mathrm{~mL}$ of solution orthophenanthroline $(O$ phenanthroline monohydrate, $\mathrm{C}_{12} \mathrm{H}_{8} \mathrm{~N}_{2} \cdot \mathrm{H}_{2} \mathrm{O}$, InLab mark) at the concentration of $0.1 \mathrm{~mol} \mathrm{~L}^{-}$ ${ }^{1}$ per dilution in $25 \mathrm{~mL}$ of ethyl alcohol and completing the volume with distilled water in a $250 \mathrm{~mL}$ volumetric flask. Subsequently it was weighed approximately $6.0 \mathrm{~g}$ of expanded perlite in a beaker and mixed with $0.1 \mathrm{~mol} \mathrm{~L}^{-1}$ orthophenanthroline solution with $6.0 \mathrm{~g}$ of expanded perlite, the mixture was left in contact for $4 \mathrm{~h}$ under constant agitation of $150 \mathrm{rpm}$ at room temperature (about $298 \mathrm{~K}$ ). At the end of the procedure, perlite was filtered through a quantitative filter paper by vacuum filtration, washing the perlite several times with water to remove the excess of orthophenanthroline solution which did no react, observing the $\mathrm{pH}$ solution (to litmus) after each water addition wash. This washing was done until reaching an approximately constant $\mathrm{pH}$, as close as possible to neutrality. The adsorbent material was dried in an oven with forced air circulation at $333 \mathrm{~K}$ for $4 \mathrm{~h}$.

All dye solutions used in this study were prepared by dilution with distilled water. The eriochrome black $\mathrm{T}$ used $\left(\mathrm{C}_{20} \mathrm{H}_{12} \mathrm{NaO}_{7} \mathrm{~S}\right)$ was prepared in aqueous medium and stored in a dark bottle.

\subsection{Adsorption experiments}

For the adsorption experiments $125 \mathrm{~mL}$ Erlenmeyer flask was used containing each $20 \mathrm{~mL}$ of eriochrome $\mathrm{T}$ black solution and 50 $\mathrm{mg}$ of perlite modified orthophenanthroline, where each represented contact times of 10 , $20,30,40,50$ and 60 minutes adsorption.

All assays were proceeded under constant agitation of $170 \mathrm{rpm}$ on a shaker table at room temperature $(298 \mathrm{~K})$. At the end of each contact time, a $5-\mathrm{mL}$ aliquot was removed with the aid of a polished glass syringe, transferred to a test tube and centrifuged for 15 minutes at $4000 \mathrm{rpm}$ to force the separation of the adsorbent from the suspension.

It was subsequently performed the absorbance reading of each aliquot in a Molecular absorption spectrophotometer in the ultraviolet-visible region in a maximum wavelength of $530 \mathrm{~nm}$ corresponding to maximum absorption length of eriochrome black T. For scans quartz cuvettes were used, the water being used as blank for obtaining the baseline.

The values of removal percentage of eriochrome $\mathrm{T}$ black color were calculated using the equation 1 .

Where, $A_{0}$ and $A_{t}$ are the absorbance values at time zero and absorbance at time $t$ respectively.

$$
\text { Color removal }(\%)=\left(\frac{A_{0}-A_{t}}{A_{0}}\right) * 100
$$

Equation 1 
2.4. Equilibrium time and study the effect of eriochrome black $T$ initial concentration in the adsorption process

For a study of the equilibrium time of eriochrome $\mathrm{T}$ black adsorption process perlite modified orto-phenatroline it was used a concentration of eriochrome black $T$ $1.0 \times 10^{-4} \mathrm{~mol} \mathrm{~L}^{-1}$ in solution $\mathrm{pH} 5$, or in natural $\mathrm{pH}$ of the dye aqueous solution. The contact time was studied 5-230 min with adsorbent mass and volume of the adsorbate $50 \mathrm{mg}$ and $20 \mathrm{~mL}$ respectively.

The value of the pollutant concentration in the case, the azo dye Eriochrome black $T$, is an important factor and was investigated. For such a test adsorption assay was performed as synthetic effluent using aqueous solutions of eriochrome black $T$ concentrations: $2.0 \times 10^{-}$ $4,1.5 \times 10^{-4}, 1.0 \times 10^{-4}$, and $3.5 \times 10^{-5}, 3.0 \times 10^{-5}$ molL $^{-1}$, the natural $\mathrm{pH}$ solution $(\mathrm{pH} 5)$, keeping constant the mass of adsorbent used $(50 \mathrm{mg})$ of expanded perlite modified orthophenanthroline and the contact time was 60 minutes.

\subsection{Effect of $\mathrm{pH}$ on the adsorption process}

For this study the influence of $\mathrm{pH}$ on eriochrome black $\mathrm{T}$ removal process, varied the $\mathrm{pH}$ of the aqueous solution of Eriochrome black $\mathrm{T}$ to the concentration of $2.0 \times 10^{-4} \mathrm{~mol} \mathrm{~L}^{-}$ ${ }^{1}$ (highest concentration) and $3.5 \times 10^{-5} \mathrm{~mol} \mathrm{~L}^{-1}$ (lower concentration, among those studied in this work), in $3.0 \mathrm{pH}$ values; 5.0 (natural pH of the aqueous solution of Eriochrome black-T) and 10.0. Time contact of 60 minutes. To study the $\mathrm{pH}$ parameter, a $\mathrm{pH}$ meter model TECNOPON PA2010 was used, where before each reading it was calibrated with the apparatus of buffer solutions $\mathrm{pH} 4$ and 7 with measurements of temperatures $298 \mathrm{~K}$.

The $\mathrm{pH}$ values were adjusted with aqueous solutions of $\mathrm{HCl}\left(1.0 \mathrm{~mol} \mathrm{~L}^{-1}\right)$ to $\mathrm{pH}$ values in the acidic range, and $\mathrm{NaOH}(1.0 \mathrm{~mol}$ $\mathrm{L}^{-1}$ ) to $\mathrm{pH}$ in the alkaline range.

\section{Results and discussion}

\subsection{Characterization of the materials}

For characterization techniques it was possible to observe changes in adsorbent characteristics attributed to the presence of ortho-phenanthroline mainly by IR and XRD. By analyzing TG/DTA of orthophenanthroline there was a total thermal decomposition of this, in the measured temperature range. The study of the thermal analysis of the modified material, showed a decrease in thermal stability, since the expanded skilled was only $2.3 \%$ of mass loss and modified orthophenanthroline adsorbent, was $13.6 \%$ of mass loss. This indicates that $11.3 \%$ of orthophenanthroline was incorporated in the expanded perlite. By the XRD analysis (Figure 1) reflections were observed related to the expanded perlite orthophenanthroline modified with the same, because the expanded perlite is presented as an amorphous aluminosilicate. By IR analysis an increase was observed in intensity and a significant enlargement of the absorption band related to the axial deformation of the $\mathrm{OH}$ bond of silanol groups belonging to expanded perlite (Si-OH) and therefore, an indication that there was an interaction between sensitive groups and liable to suffer chemical interaction (silanols groups) of expanded perlite with the basic sites of the Bronsted orthophenanthroline. ${ }^{12}$ 


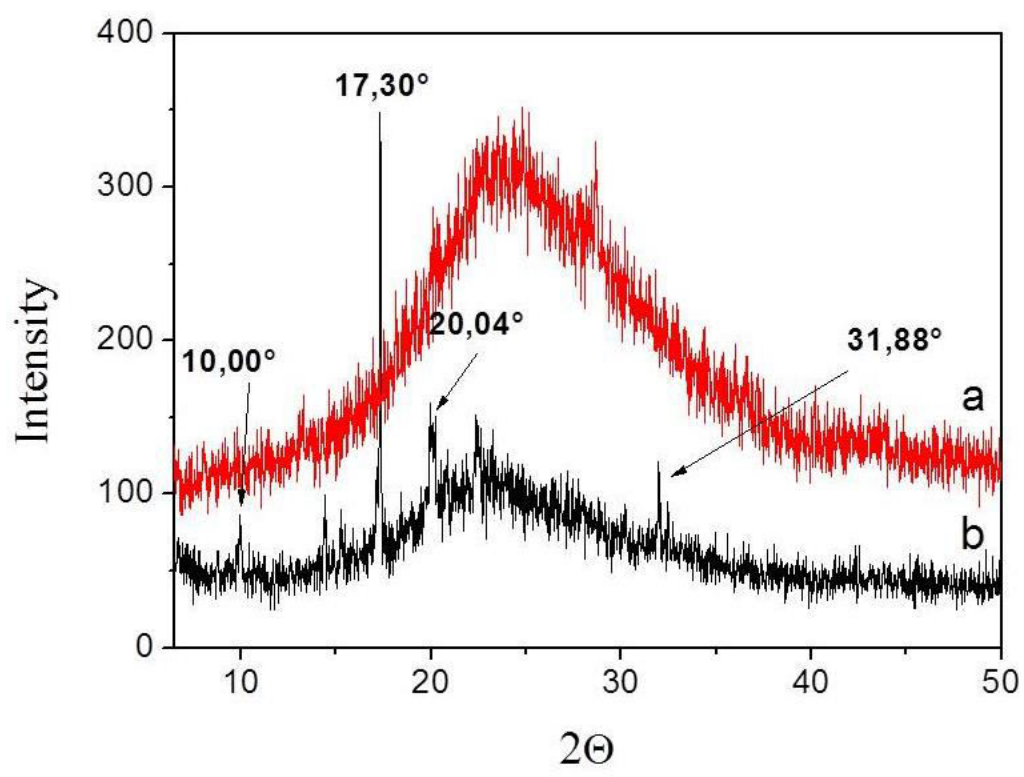

Figure 1. a) XRD of expanded perlite and b) XRD of expanded perlite modified orthophenanthroline

3.2. Equilibrium time and study of the eriochrome black $T$ initial concentration effect in the adsorption process

This removal process was analyzed in order to verify the process applicability and improve the conditions of analysis for this research and assess whether there is an adsorption equilibration time. The Figure 2 shows the amount of eriochrome black $T$ ( $\mathrm{mg}$ ) removed per mass unit of adsorbent $(\mathrm{g})$, called $\mathrm{Q}\left(\mathrm{mg} \mathrm{g}^{-1}\right)$ versus the contact time in minutes.

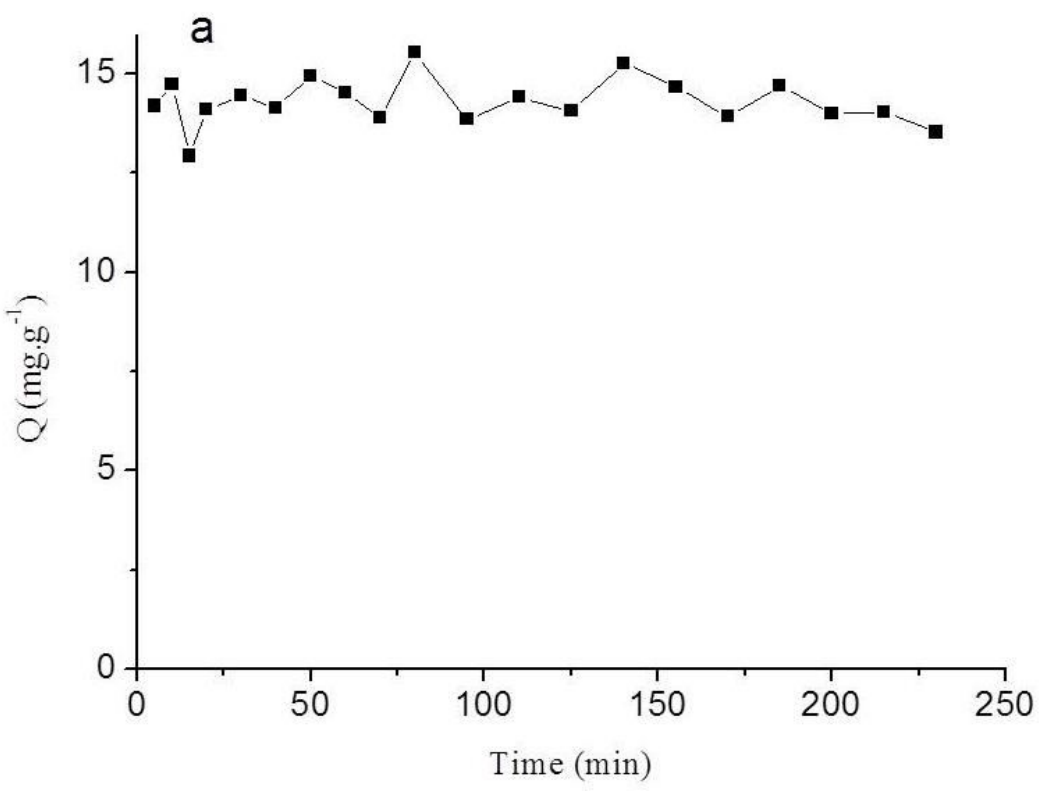

Figure 2. Removal of Eriochrome black-T versus the contact time (Q) 
The maximum removal of eriochrome $\mathrm{T}$ black color reaches $100 \%\left(15.56 \mathrm{mg} \mathrm{g}^{-1}\right)$ in 80 min. The average removal percentage of black color from the eriochrome T during this adsorption process corresponds to $91.95 \%$ of color removal at the conditions expressed previously in the study herein, so this means an excellent color removal amount of this azo dye by perlite modified orthophenanthroline.

The adsorption process is a physicalchemical phenomenon that depends on many factors such as the adsorbent porosity, the adsorbate molecule size and especially the type of interaction between the adsorbate and the adsorbent. in this study it is noticed that there was a rapid saturation of the adsorbent $(95.22 \%$ removal of color in 5 minutes adsorption), correlated to the type of interaction between the eriochrome black
$T$ molecules and the surface of the perlite modified with orthophenanthroline, which is a relatively weak interaction, being a superficial acid-base interaction (as well as the modification of the expanded perlite with orthophenanthroline is also superficial).

It can be said that the adsorbate molecules are adsorbed and desorbed with great ease from the active adsorbent sites, being thus unable to observe a time balance, i.e., the adsorption molecules rate on the surface are not equal to the molecules rate desorption.

Figure 3 shows photographs of color removal process. The photographs show the adsorbent saturation with eriochrome black $T$ (b) and the complete removal of dye color in 80 minutes of treatment by adsorption (c and d).

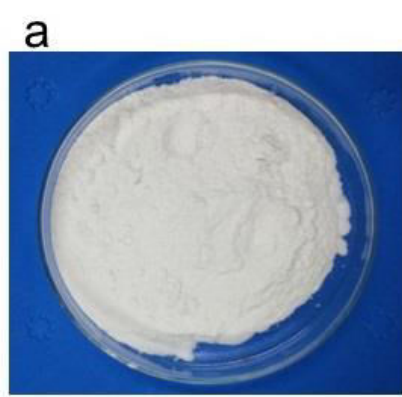

b

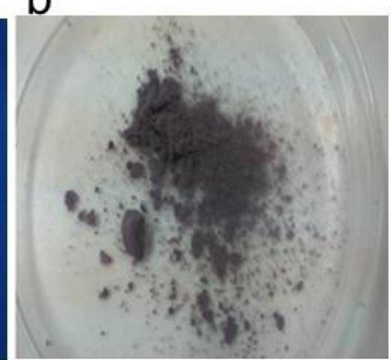

C

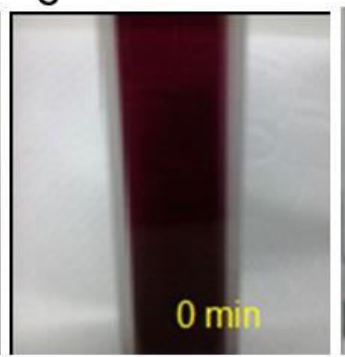

d

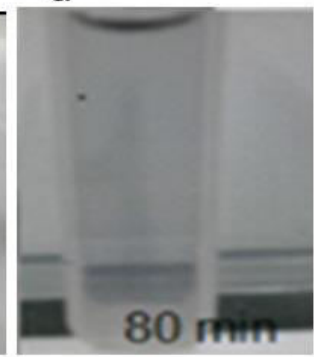

Figure 3. a) expanded perlite b) expanded perlite after adsorption (saturated with Eriochrome black-T) and Maximum color removal of Eriochrome black T solution in 80 min (c, d)

Through the images (Figure 3) it was observed the complete removal of the black color of eriochrome $\mathrm{T}$ by the expanded perlite modified with orthophenanthroline, indicating that this adsorption process is valid and effective.

The effect of varying the dye concentration was evaluated because this is an important parameter for the solid-liquid adsorption process. This study was done by varying the concentration of adsorbate in the natural $\mathrm{pH}$ of the solution $(\mathrm{pH} 5.0)$ and maintaining constant the adsorbent mass under the analysis conditions described in the experimental methodology of this study. Figure 4 (a) shows the amount of dye removed (mg $\mathrm{g}^{-1}$ ) versus time ( $\mathrm{min}$ ), illustrating the effect of varying the initial concentration of Eriochrome black $T$ in the adsorption process. 


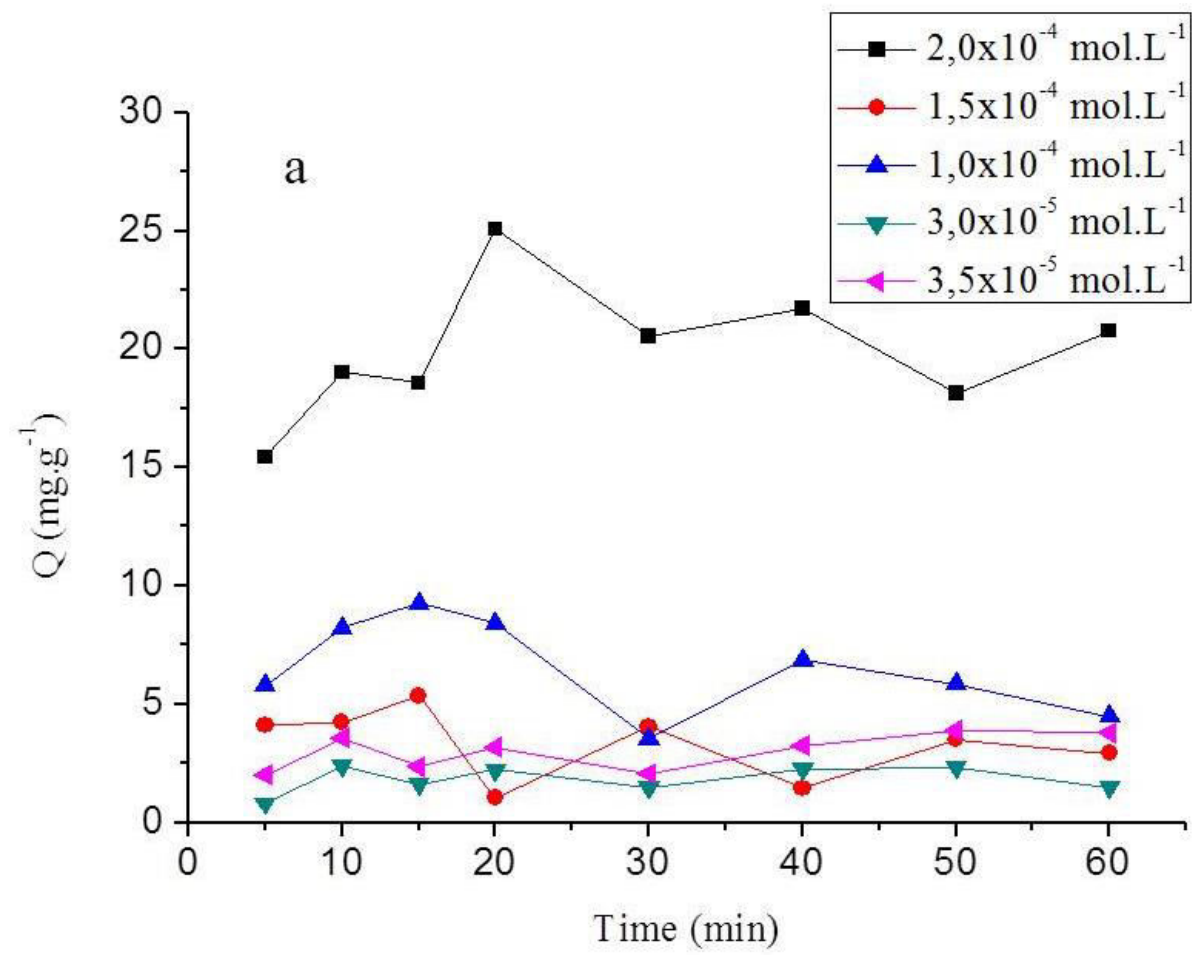

Figure 4. Effect of varying the initial concentration of Eriochrome black-T

It is verified that for a higher value of the Eriochrome black-T concentration, in the case $2.0 \times 10^{-4} \mathrm{~mol} \mathrm{~L}^{-1}$, it was obtained the highest amount of removal percentage of black color eriochrome $\mathrm{T}$, with $63.74 \%$ of removal within 20 minutes of contact, where this corresponds to removal of $25.06 \mathrm{mg} \mathrm{g}^{-1}$ of Eriochrome black-T. This was the best color removal value compared to the values of other concentrations of this study. By increasing the concentration of adsorbate, it is also increased the removal percentage of dye by the expanded perlite as the adsorbate. Whereas at low concentrations the ratio of the number of molecules per surface area available for dye adsorption is minimum, and consequently an increase in the initial dye concentration increases the amount of dye adsorbed on the expanded perlite. $^{11,13}$

Figure 5 shows the photographs obtained after 20 min of adsorption for dye removal at the highest concentration in this study $\left(2.0 \times 10^{-4} \mathrm{~mol} \mathrm{~L}^{-1}\right)$ with $63.74 \%$ of color removal.

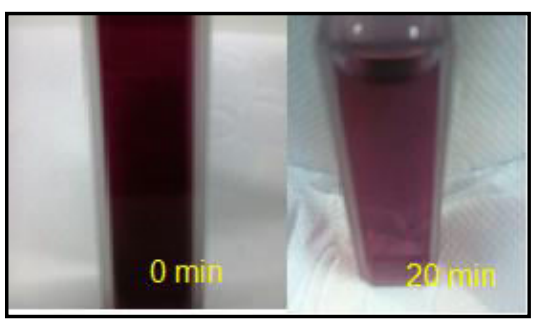

Figure 5. Photos of Eriochrome black T solution $2.0 \times 10^{-4} \mathrm{molL}^{-1}$ after 20 min treatment 


\subsection{Effect of $\mathrm{pH}$ on the adsorption process}

$\mathrm{pH}$ is one of the most relevant parameters in the adsorption process, because the structure properties of the adsorbent surface and the adsorbate itself can be affected and alter the efficiency of the dye removal process by the treatment in question.

A change in the $\mathrm{pH}$ of the aqueous phase can affect the adsorption process in terms of its effect on the loading surface of the adsorbate or the ionization degree. As the $\mathrm{pH}$ of the aqueous phase decreases, the solid surface will become more positive or less negative depending on the adsorption of charged sites of the solution protons, resulting in increased anions adsorption and cations decreased adsorption. The reverse occurs when increasing the $\mathrm{pH}$ of the solution.

The influence of the $\mathrm{pH}$ of the Eriochrome black- $\mathrm{T}$ solution was investigated at three $\mathrm{pH}$ values: 3.0, 5.0 (natural $\mathrm{pH}$ of the aqueous solution of Eriochrome black-T) and 10.0. Figure 6 shows the percentage of removal of dye color curve by varying the $\mathrm{pH}$ of the dye solution in the above-mentioned range over time. It was investigated the effect of $\mathrm{pH}$ on the removal process for two dye levels: the highest concentration $\left(2.0 \times 10^{-4} \mathrm{~mol} \mathrm{~L}^{-1}\right)$ and the lowest $\left(3.5 \times 10^{-5} \mathrm{~mol} \mathrm{~L}^{-1}\right)$.

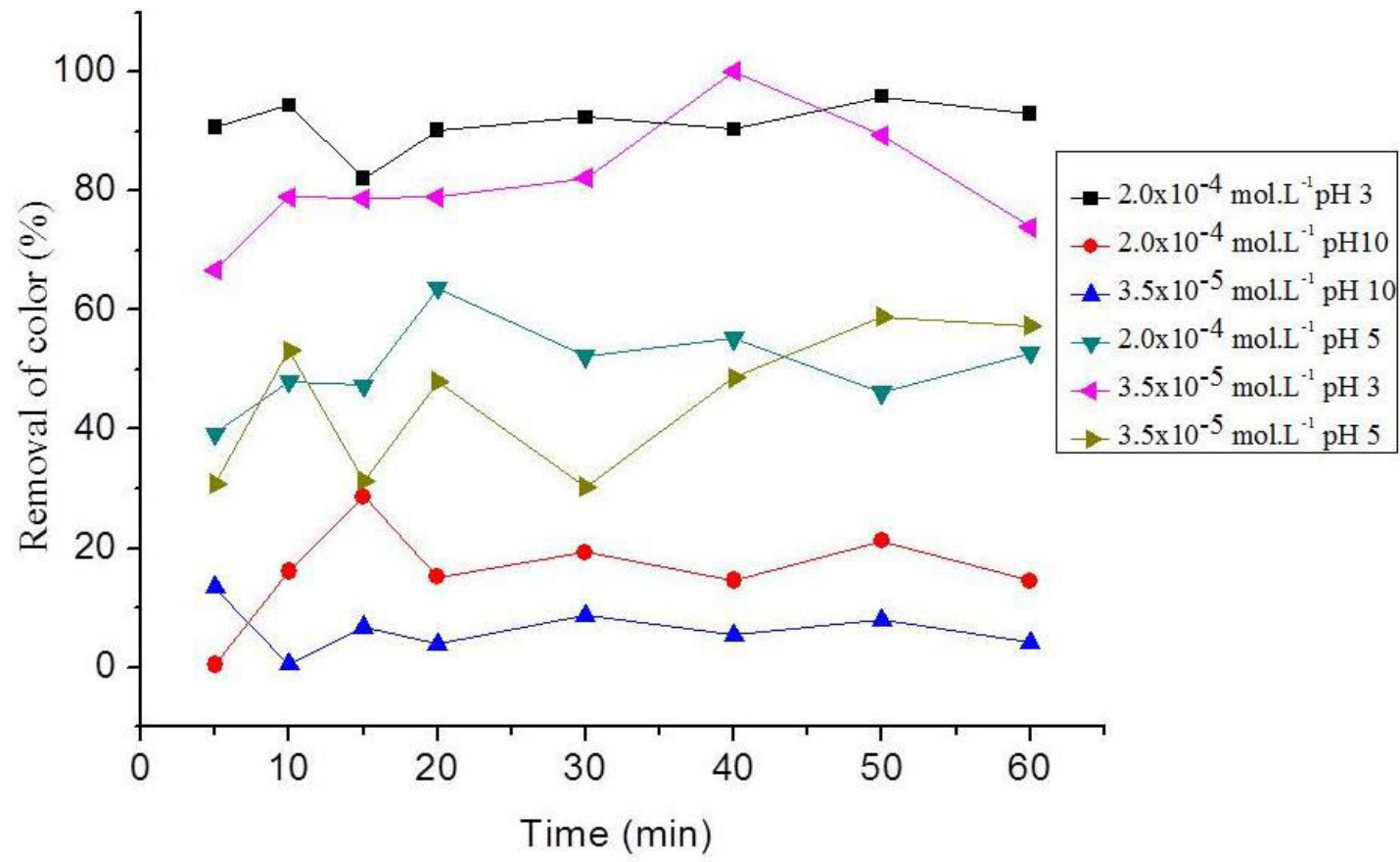

Figure 6. Effect of $\mathrm{pH}$ variation in the adsorption process

It was obtained as a result that the adsorption process is more effective when the $\mathrm{pH}$ of the solution is changed to more acidic range, specifically at $\mathrm{pH} 3$ for the two concentrations tested, being obtained $100 \%$ of the dye color removal $\left(6.62 \mathrm{mg} \mathrm{g}^{-1}\right)$ in a concentration of eriochrome black $\mathrm{T} 3.5 \times 10^{-5}$ $\mathrm{mol} \mathrm{L}^{-1}$ at $\mathrm{pH}$ 3. This maximum removal occurred in 40 minutes adsorption. In an alkaline medium ( $\mathrm{pH} 10)$ it was not obtained a good result of dye color removal.

The maximum amount of color removal at this $\mathrm{pH}$ was $28.50 \%$ in 15 minutes for adsorption to concentration $2.0 \times 10^{-4} \mathrm{~mol} \mathrm{~L}^{-1}$. The effective removal of Eriochrome black $T$ in $\mathrm{pH} 3$ by perlite modified orthophenanthroline is a result of acid-base interaction between the adsorbate and the adsorbent, since too much acid in this 
medium theeriochrome black $T$, considered an azo dye has its sulfonic protonated groups (acidic sites) fostering the interactions with basic sites of expanded pearlite modified with orthophenanthroline.

Therefore, the environment acidity is an important factor influencing the interaction between adsorbent and adsorbate with respect to electrostatic interactions.

These results demonstrate that the more acid the medium is, the most efficient is the eriochrome $\mathrm{T}$ black solution color removal process by adsorption with perlite modified with orthophenanthroline. The photographs shown in Figure 7 shows the process of color over time of removal to the maximum concentration and the minimum dye, used in this study, it is clearly evident that in the alkaline medium ( $\mathrm{pH} 10)$ removal is minimal, and acidic $\mathrm{pH}(\mathrm{pH} 3)$ removal is maximum for both concentrations.
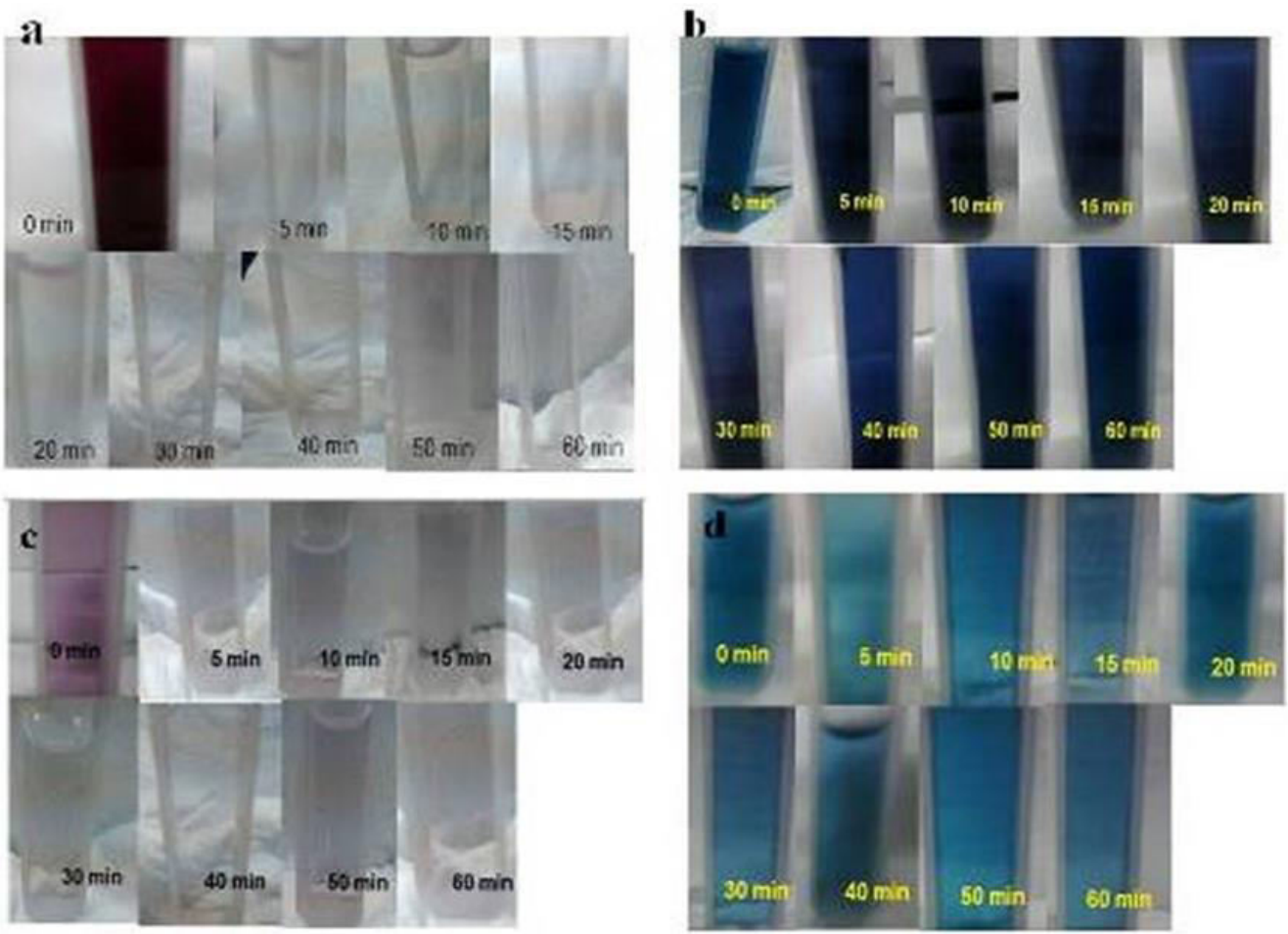

Figure 7. Photographs of the color removal process: $\left.2.0 \times 10^{-4} \mathrm{~mol} \mathrm{~L}^{-1}(\mathrm{a}) \mathrm{pH} 3 \mathrm{~b}\right) \mathrm{pH} 10$ and $3.5 \times 10^{-5} \mathrm{~mol} \mathrm{~L}^{-1}$ (c) $\mathrm{pH} 3$ and (d) $\mathrm{pH} 10$

\section{Conclusion}

In the present study, we carried out the study of eriochrome $T$ black removal using the expanded perlite orthophenanthroline modified by adsorption technique. The study of the adsorption process was performed by investigating the effect of the dye initial concentration, the contact time, and $\mathrm{pH}$ range of the solution (acidic and alkaline range) in the adsorption process, for a so-called synthetic effluent (aqueous solution of eriochrome black T).

Characterizations techniques employed showed that there were changes in the expanded perlite caused by the presence of orthophenanthroline, in the merging process. At the equilibration time of the study, during the time range studied $(5-230 \mathrm{~min}$ ) it was verified that there was a very rapid adsorbent saturation, probably attributed to the kind of interaction between the eriochrome black $T$ and the expanded perlite modified 
orthophenanthroline, It is a superficial origin interaction between dye acid sites and orthophenanthroline basic sites, incorporated into the perlite surface. In the study of the initial adsorbate concentration effect in the case $2.0 \times 10^{-4} \mathrm{~mol}$ $\mathrm{L}^{-1}$ natural $\mathrm{pH}(\mathrm{pH} 5)$, gave the highest removal percentage value of eriochrome $T$ black color with $63.74 \%$ removal within 20 minutes of contact. It was observed that the increase of the initial dye concentration, favors the increase of the percentage of perlite modified by adsorption with orthophenanthroline, as in low concentrations of adsorbate the ratio of the number of molecules per superficial specifias inea available for dye adsorption is minimum, consequently an increase in dye initial concentration increases the amount of dye adsorbed on the expanded and modified perlite. ${ }^{5,6}$

When evaluating the effect of the $\mathrm{pH}$ variation of eriochrome black $\mathrm{T}$ solution in the adsorption process, it was concluded that the more acid environment is, the greater the percentage of stain removal, this being a result of acid-base interaction between the adsorbate and the adsorbent, since amid a large concentration of protons, the eriochrome black $T$ acid is in the azoprotonated form fostering interactions between the dye sulfonic groups (protonated) and the basic sites of perlite modified with orthophenanthroline. In the acidic range of $\mathrm{pH} 3100 \%$ removal of eriochrome $\mathrm{T}$ black color was reached to the concentration of $3.5 \times 10^{-5} \mathrm{~mol} \mathrm{~L}^{-1}$. At alkaline $\mathrm{pH}$ the dye removal was minimal, only 28.50 $\%$ of color removal.

Thus it can be concluded that the expanded perlite (an aluminosilicate naturally acid) modified with orthophenanthroline (one Bronsted base) consists of an effective material for the dyes removal of this type in acid aqueous solutions under the conditions shown in this study. And in this context it is also validated the application of adsorbent in removing these types of dye (acid) in actual wastewater containing them, under the conditions noted in the scientific study herein.

\section{References}

${ }^{1}$ De Luna, M. D. G.; Flores, E. D.; Genuino, D. A. D.; Futalan, C. M.; Wan, M.-W. Adsorption of Eriochrome Black $T$ (EBT) dye using activated carbon prepared from waste rice hulls - Optimization, isotherm and kinetic studies. Journal of the Taiwan Institute of Chemical Engineers 2013, 44, 646 [CrossRef]

${ }^{2}$ Hamed, M. M. A.; Ismail, N. M.; Ibrahim, S. A. Solvent Characteristics in the Spectral Behaviour of Eriochrome Black T. Dyes and Pigments 1994, 26, 297. [CrossRef]

${ }^{3}$ Barka, N.; Abdennouri, M.; El Makhfouk, M. Removal of Methylene Blue and Eriochrome Black $T$ from aqueous solutions by biosorption on Scolymus hispanicus. L.: Kinetics, equilibrium and thermodynamics. Journal of the Taiwan Institute of Chemical Engineers 2011, 42, 320. [CrossRef]

${ }^{4}$ Dogan, M.; Alkan, M. Removal of methyl violet from aqueous solution by perlite. Journal of Colloid and Interface Science 2003, 267, 32. [CrossRef]

${ }^{5}$ Dogan, M.; Alkan, M.; Turkyilmaz, A.; Ozdemir, $Y$. Kinetics and mechanism of removal of methylene blue by adsorption onto perlite. Journal of Hazardous Materials 2004, 109, 141. [CrossRef]

${ }^{6}$ Acemioglu, B. Batch Kinetic study of sorption of methylene blue by perlite. Chemical Engineering Journal 2005, 106, 73. [CrossRef]

${ }^{7}$ Roulia, M.; Vassiliadis, A. A. Interactions between C.I. Basic Blue 41 and aluminosilicate sorbents. Journal of Colloid and Interface Science 2005, 291, 37. [CrossRef]

${ }^{8}$ Dogan, M.; Alkan, M.; Çakir, U. Electrokinetic Properties of Perlite. Journal of Colloid and Interface Science 1997, 192, 114. [CrossRef]

${ }^{9}$ Chassapis, K.; Roulia, M.; Vrettou, E.; Parassiris, A. Preparation of bioinorganic fertilizing media by adsorption of humates on 
glassy aluminosilicates. Colloids and Surfaces B: Biointerfaces 2010, 81, 115. [CrossRef] ${ }^{10}$ Sari, A.; Sahinoglu, G.; Tuzen, M. Antimony(III) Adsorption from Aqueous Solution Using Raw Perlite and Mn-Modified Perlite: Equilibrium, Thermodynamic, and Kinetic Studies. Industrial \& Engineering Chemistry Research 2012, 51, 6877. [CrossRef]

${ }^{11}$ Jing, G.; Wang, L.; Yu, H.; Amer, W. A.; Zhang, L. Recent progress on study of hybrid hydrogels for water treatment.
Colloids and Surfaces A: Physicochemical and Engineering Aspects 2013, 416, 86. [CrossRef]

${ }^{12}$ Almeida, J. M. F.; Dissertação de Mestrado, Universidade Federal do Rio Grande do Norte, 2015. [Link]

${ }^{13}$ Govindasamy, V.; Subramanian, S.; Sahadevan, R.; Maherdradas, D. K. Removal of Malachite Green from Aqueous Solutions by Perlite. International Journal of Chemical Reactor Engineering, 2009, 7, 1. [Link] 